\title{
VERIFYING THE POSSIBILITIES OF USING A 3D LASER SCANNER IN THE MINING UNDERGROUND
}

\author{
Vlastimil KAJZAR *, Radovan KUKUTSCH and Nikola HEROLDOVÁ
}

Institute of Geonics, Academy of Sciences of the Czech Republic, v.v.i., Studentská str. 1768,

70800 Ostrava-Poruba, Czech Republic

*Corresponding author's e-mail: vlastimil.kajzar@ugn.cas.cz

\begin{tabular}{l} 
ARTICLE INFO \\
\hline Article history: \\
Received 4 September 2014 \\
Accepted 29 January 2015 \\
Available online 11 February 2015 \\
\hline
\end{tabular}

Keywords:

3D laser scanning

Underground

Mining

Leica ScanStation $\mathrm{C} 10$

\begin{abstract}
Presented contribution introduces our current utilization knowledge of the pulse scanner Leica ScanStation C10 in situ mine workings. It is a device with a long-range laser beam that has excellent positional, length and angular accuracy and a very high speed laser scanning with a possibility of photographic documentation of scanned scene.

The possibility of its use in mining conditions was tested in mine workings in closed polymetallic deposit of Zlaté Hory (Olomouc region, Czech Republic). Within realized surveying campaigns, the possibilities of using this technology were verified, especially for documentation of the current technical condition of the mines and their real spatial definition. Furthermore, it is possible to monitor and determine the spatial changes in mine features (movements and deformations).

The analysis of the data based on the undertaken scanning campaigns and also with regard to the physical and technical constraints that were encountered, the technological procedures of each type of scanning were subsequently adjusted to the specific conditions.
\end{abstract}

\section{INTRODUCTION}

Laser scanning systems excel in ability to contactless determine spatial coordinates of any spatial objects, such as buildings, structures, interiors, space, terrain, etc. and with exceptional speed, accuracy, complexity and safety. The scanned object is then visualized by specialized software as the cloud of points. Subsequently, it is possible to perform a wide range of analytical tasks and also to generate models of the object.

The basic principle of the device works in the similar way to radar. The device emits a pulse and captures its reflection. It is possible to calculate the distance to the point of reflection based on the time between sending the pulse and receiving back its reflection. Due to pulse transmission of the narrow laser beam in different directions in a relatively short period of time (thousands to hundreds of thousands emitted pulses per second), it is possible to target individual spatial scene with high precision and resolution. The spatial position of each point is thereafter calculated by spatial polar method.

In the context of well-known practice, using 3D laser scanner in mining environment was so far very limited in the Czech Republic. The principles of 3D laser scanning are used in the Czech Republic for more than 10 years. This technology is used mainly in geotechnology in terms of surveying the real condition of tunnels and adits, assessment of lining shape and other building components, volume of overbreaks (e.g. tunnels Klimkovice, Dobrovského, Panenská, Lochkov and Prague underground constructions). (Středa, 2011; Vaníček, 2012).
This technology also starts to take over in quarries for the purpose of topographic mapping or monitoring of advance of the quarry material and determination of the volume of such material etc. (project references of Arcadis, Geotronics or Severočeské doly company).

From a global point of view, the published papers by e.g. Huber and Vandapel (2003), Somervuori and Lamberg (2009), Jonsson et al. (2009), Fekete et al. (2010), Xiling et al. (2011) or Feng (2012) are worth mentioning.

The wider utilization of this technology is in cave rooms, not only in the Czech Republic, but also abroad (Buchroithner, 2009; Cosso et al., 2014). Unfortunately, the use of this technology is still limited in mining environment, with some exceptions (e.g. DMT GmbH or Measurement Devices Ltd. UK). But this technology has never been used in the Czech Republic so far.

A small frequency of its use is determined not only by the price of the device, but also primarily by the specifics of such environment. At the Institute of Geonics, there was a possibility to use this method in situ followed by several tests in the specific mining conditions in order to develop scanning methods in different types of mines. It should solve mostly for purpose of documentation of current technical condition of mines, for their actual spatial surveying and also for the possibility of monitoring the spatial changes of mining objects (e.g. movements and deformations). This task is important for scanning both, existing and historic mine workings. In the paper, the attention is also paid to possible restrictions 
of using the laser scanner technology based on such difficult conditions.

Based on the realized campaigns, subsequent analysis and knowledge's of physical and technical limitations, the technological scanning procedures for each type of scanned objects were specified.

\section{ORE MINES JESENÍK, ZLATÉ HORY LOCALITY}

Zlaté Hory locality is located about $7 \mathrm{~km}$ from the Zlaté Hory town. This locality is a historical mining district, where the ore mining dates back to the 14 th century. Since that time, there has been several times a boom and recession of mining. The last stage of mining here has been implemented in the postwar years until the 90 s of the 20th century. Thanks to the political and social changes, the ore mining industry underwent a restructuralization. Therefore, all ore mines, except uranium mines, have been shut down in the Czech Republic.

In the latest stage of mining in Zlaté Hory, $7184.4 \mathrm{kt}$ monometallic and polymetallic ores incl. gold was mined in total. Opening of ore deposit was provided by 4 pits, 14 adits, 4 slope adits and 11 chutes. The total length of the mine workings exceeds $140 \mathrm{~km}$ (Vranka and Kukutsch, 2011).

The Zlaté Hory locality has not been chosen for the purpose of 3D laser testing randomly. After the year 1990, this locality has been considered as one of the potencial places where to build an underground mining research base and it was planned primarily for the service and research purposes. Unfortunately, the lack of consensus led to complete failure of all plans and this idea ended only in stage of detailed study. Although, after more than 15 years, the working place like this was needed again. Therefore, the Josef adit near Mokrsko is being used for these purposes in present days. The big advantage of testing in Zlaté Hory location is zero operational activity, because none of mine workings belong to the category of mines in operation. Thus, it was possible to verify the potential of laser scanning in mining environment with its specific features, which can be expected in such difficult conditions. In the environment of Zlaté Hory-East and Zlaté Hory-South, the mines were scanned with both, spatial and surface variability. The linear and also large mine workings, mine workings with and without dipping, reinforced and nonreinforced, dry, half flooded or flooded parts were scanned.

\section{LASER SCANNING IN MINING UNDERGROUND}

Since 2011, the Institute of Geonics disposes and actively utilizes a static terrestrial laser scanning system. Particularly, it deals with the Leica ScanStation C10 of Leica Geosystems AG. It is a compact pulse scanner with dual-axis compensator, featuring high speed scanning (up to 50000 points per second), high surveying precision and long-range beam.
The device uses the green laser beam with wavelength of $532 \mathrm{~nm}$. Based on the intensity of reflected beam, the device can distinguish different types of planes within the point cloud. There is a possibility of scanning in the full field of view (see Fig. 1). ScanStation $\mathrm{C} 10$ is able to measure on distance up to $300 \mathrm{~m}$ in ideal reflectivity conditions. The shortest distance of detection is $0.1 \mathrm{~m}$. The device is also complemented by integrated digital camera.

In terms of spatial resolution scanning, the closer the scanned object is the closer the points defining the object are to each other (see Fig. 2). The device is able

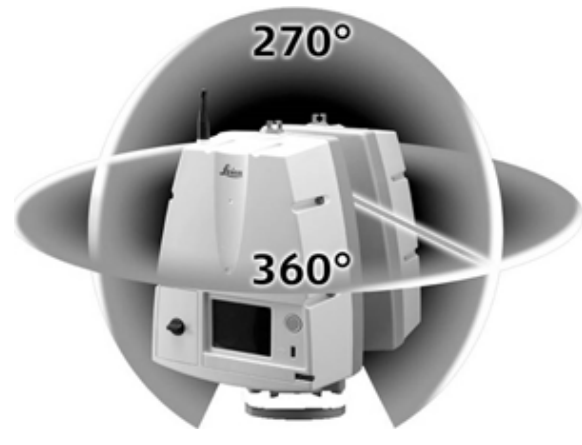

Source: Leica Geosystems AG

Fig. 1 Full field of view of the scanner Leica ScanStation C10.

to distinguish different points in mutual distance of $1 \mathrm{~mm}$.

The indicated $3 \mathrm{D}$ accuracy of measured points is $6 \mathrm{~mm}$ which means that the real distance between the device and the object is $4 \mathrm{~mm}$. The angular accuracy is $60 \mu \mathrm{rad}$ (see Fig. 3). More accurate determination of accuracy is the matter of repetitive and comparative measurements and statistical evaluations. However, the range in millimeters is more than adequate for the wide-variety of utilization requesting the accuracy in centimeters.

\section{LIMITING FACTORS OF UNDERGROUND SCANNING}

The primary application of laser scanning is to capture the current condition of mines. The quality of the resulting scanned point clouds depends on many factors. It showed up, that not only the limiting factors, but also the very limitations of the device equipment are based on the specific characteristics of the mining environment. There are several limitations while scanning underground:

- inadequate lighting conditions, respectively darkness (problematic stabilization of surveying apparatus, problems with visibility of targets, the limitations of the integrated camera, etc.),

- dust (reduced visibility in mine workings, the need of filtration of the air flowing into the scanner, etc.), 


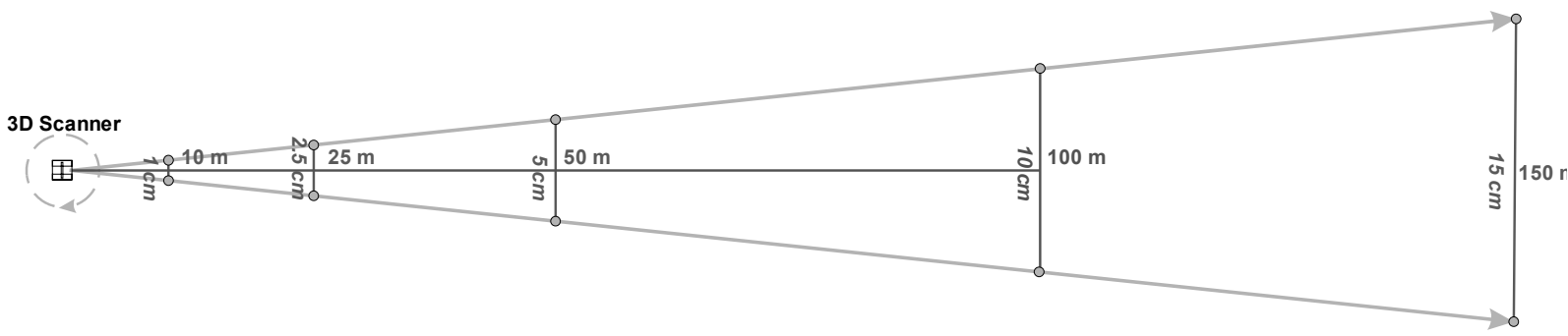

Fig. 2 Planar view on two consecutive scan lines in spatial resolution of 10x10 cm, at $100 \mathrm{~m}$ distance and adequate theoretical resolution for other distances (Kuda et al., 2014).

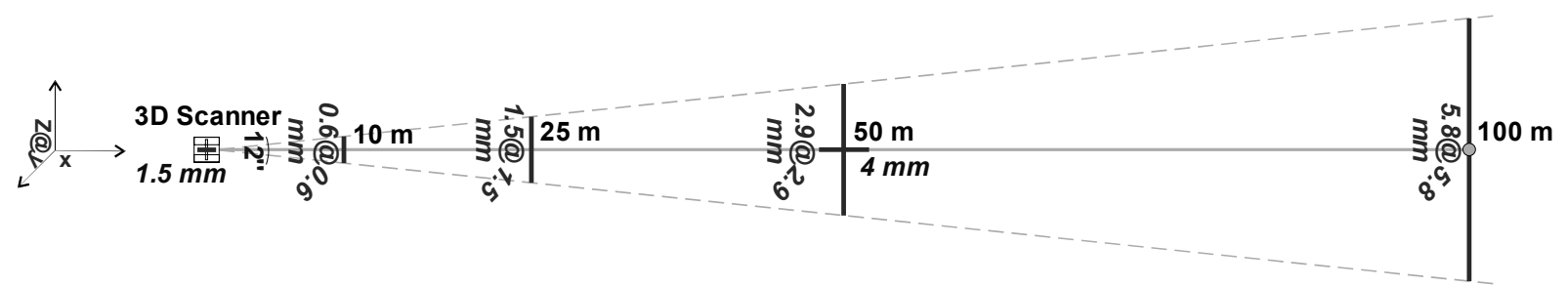

Fig. 3 Schematic overview of the basic measurement errors for ScanStation C10 (Kuda et al., 2014).

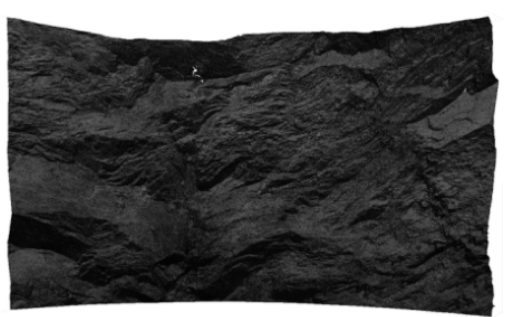

Highest Resolution

$0.02 \mathrm{~m} / 100 \mathrm{~m}$

Scanned window: $30 \mathrm{~min}$

Full field of view: $170 \mathrm{~min}$

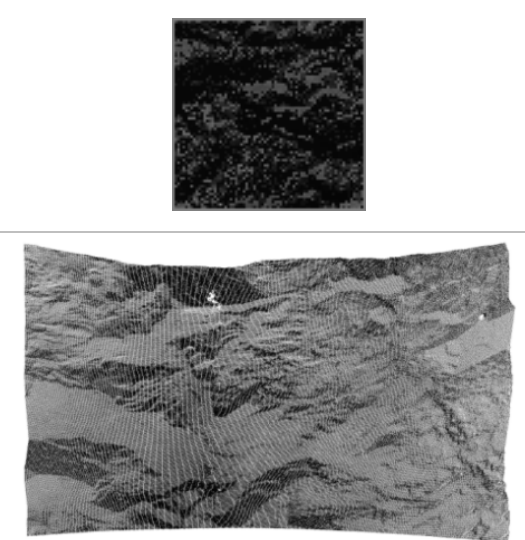

Medium Resolution

$$
0.10 \mathrm{~m} / 100 \mathrm{~m}
$$

Scanned window: $2: 15 \mathrm{~min}$

Full field of view: $7 \mathrm{~min}$

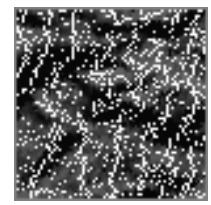

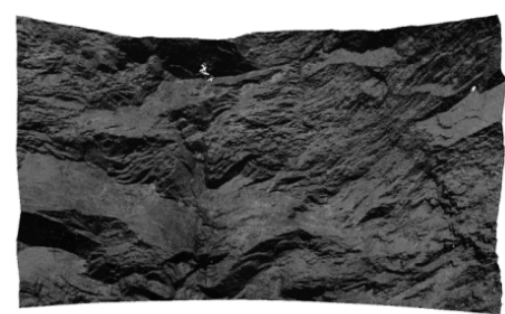

High Resolution

$0.05 \mathrm{~m} / 100 \mathrm{~m}$

Scanned window: $9 \mathrm{~min}$

Full field of view: $28 \mathrm{~min}$
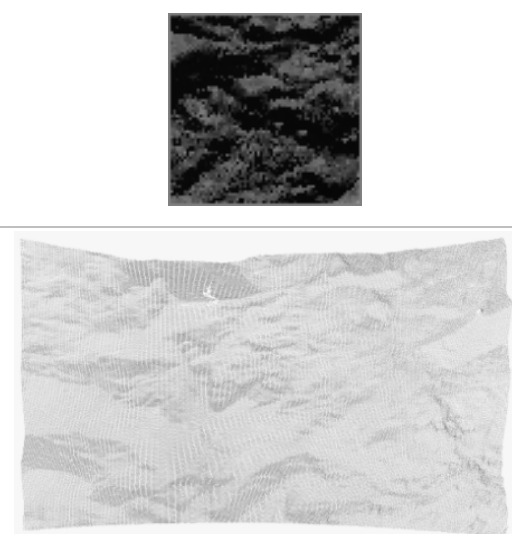

Low Resolution

$0.20 \mathrm{~m} / 100 \mathrm{~m}$

Scanned window: $1 \mathrm{~min}$ Full field of view: 1:45 min

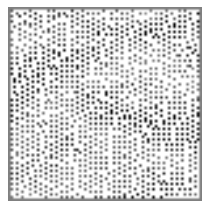

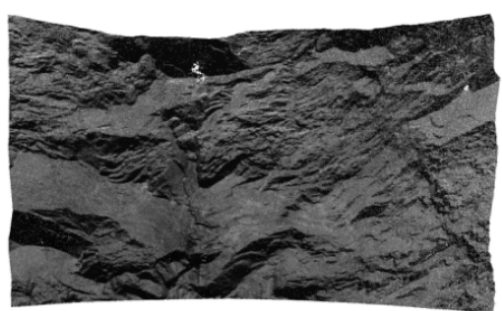

Custom Resolution $0.07 \mathrm{~m} / 100 \mathrm{~m}$

Scanned window: 4:30 min

Full field of view: 14 min
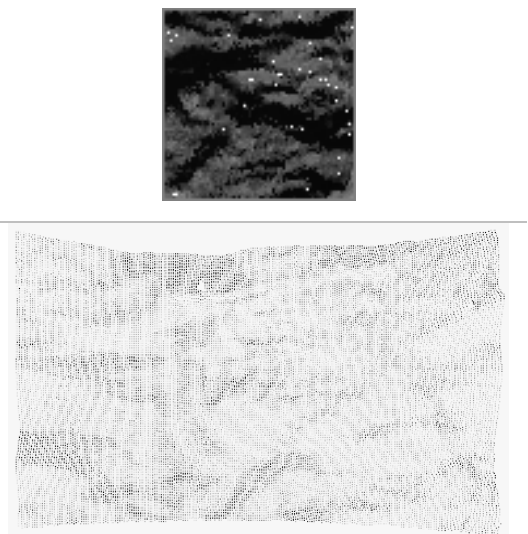

Custom Resolution

$0.50 \mathrm{~m} / 100 \mathrm{~m}$

Scanned window: 0:15 min Full field of view: 0:45 min

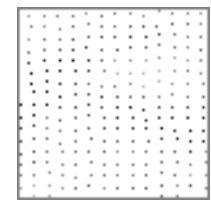

Fig. 4 Dependence of the duration and density of scanning on the type of spatial resolution. 


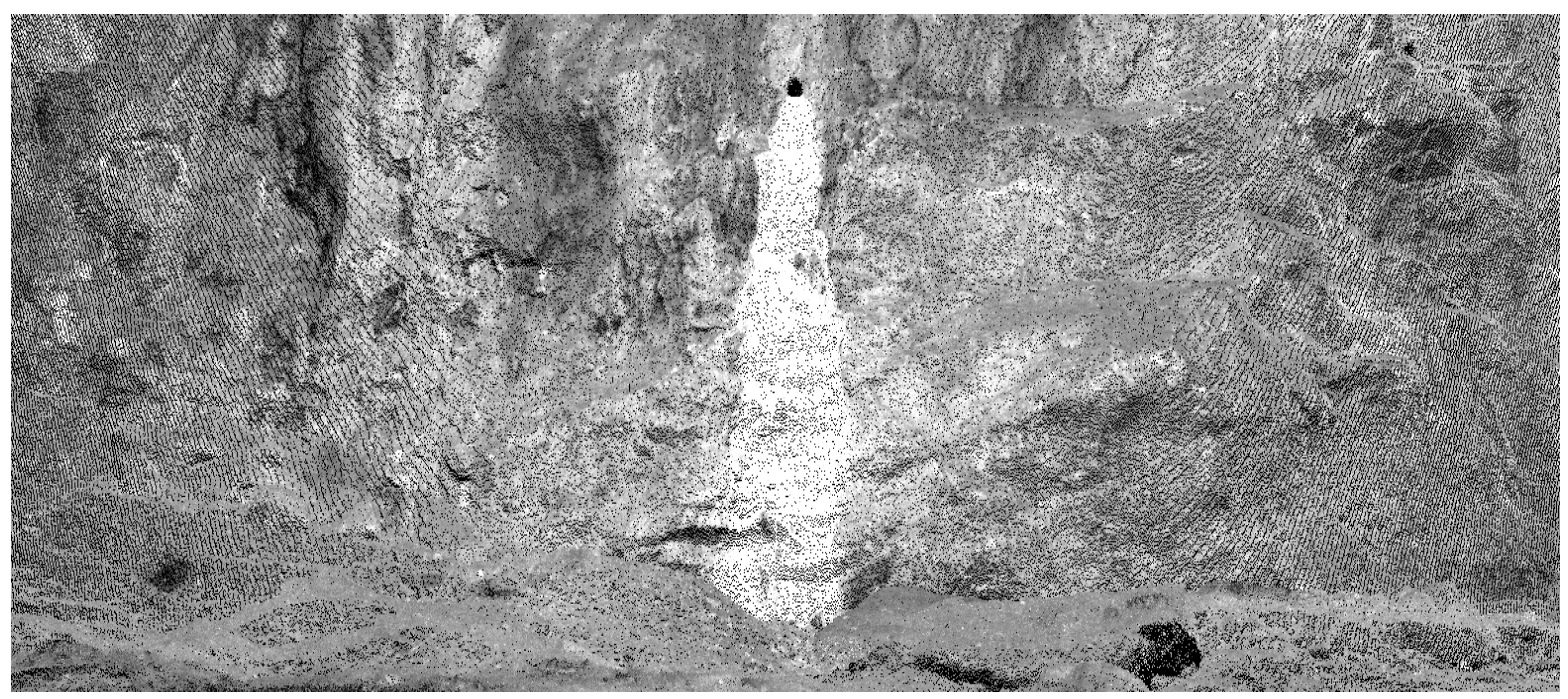

Fig. 5 Albedo on example of copper discharges, so-called "Blue Lady".

- humidity (condensation, corrosion limiting the placement of magnetic targets on the steel reinforcement of mines, etc.),

- water (on the floor, dripping, flowing),

- temperature of the rock mass and the surrounding environment (on the limits of device operating temperature),

- noise (difficulties in communication between team members),

- weight and dimensional parameters of devices and accessories, requirement to careful handling, complicated portability,

- limited maneuver space,

- difficult access to mines (the slopes, obstacles in the mine, etc.),

- disturbance stability of mine workings,

- continuous operating activity in mines,

- requirements for intrinsic safety (in areas with potentially explosive mine air),

- the need for continuous monitoring of the mine conditions

- $\quad$ and many others.

The important advantages, in terms of device utilization, are the declared dust and humidity resistance (IP54) and operating temperature range from $0^{\circ} \mathrm{C}$ to $40^{\circ} \mathrm{C}$ and also the associated battery life to it. The limiting scanning conditions are those cases, when it is impossible to obtain the relevant data due to difficult accessibility of scanned area, for instance scanning in either narrow or vertical mine workings usually accessible only from above or from the bottom. Another limiting condition that we were confronted with was the high humidity and subsequent condensation of water vapour on the device.

\section{SCANNING RESOLUTION OPTIMIZATION}

The main factor of the quality of outputs that can be influenced is the scanning resolution setting. The goal of one of the initial scanning campaign was therefore to verify the scanner possibilities in the terms of testing the scanner resolution. For better orientation in this field Figure 4 was created. It presents the dependence of scanning time on the type of selected spatial resolution. Given times describe the execution time of scanning of the rock mass defined by scanning window (in this case the size is about $3.2 \times 1.8 \mathrm{~m}$ ), respectively the full field of view (see Fig. 1). The point density of final point cloud is clearly demonstrated in $0.2 \times 0.2 \mathrm{~m}$ detail below.

\section{THE DIFFERENT LEVELS OF REFLECTIVITY}

Another key factor of the quality of outputs, which can be not influenced, is called albedo, expressing the reflectivity level of the object, resp. its surface. It is the ratio of the reflected electromagnetic radiation to the amount of incident radiation. This attribute of various types of the materials can significantly affect obtained output. It also shows that another problematic factor was scanning of the dark, highly reflective or transparent materials (Štroner et al., 2013).

A very good example of different levels of reflectivity is shown in Figure 5. A phenomenon socalled "Blue Lady", represented by the brighter patch, is captured in this image. In fact, it is a flat coating of a blue color caused by overflowing allophane.

A well-known material, which negatively affects the scanning outputs, is glass, but it rarely appears in a mining environment. Another substance with the similar properties is water, respectively the water surface. The result in the scan is either completely empty space, because the beam has no chance to bounce or, in some cases, also scanned reflection of surrounding objects. 

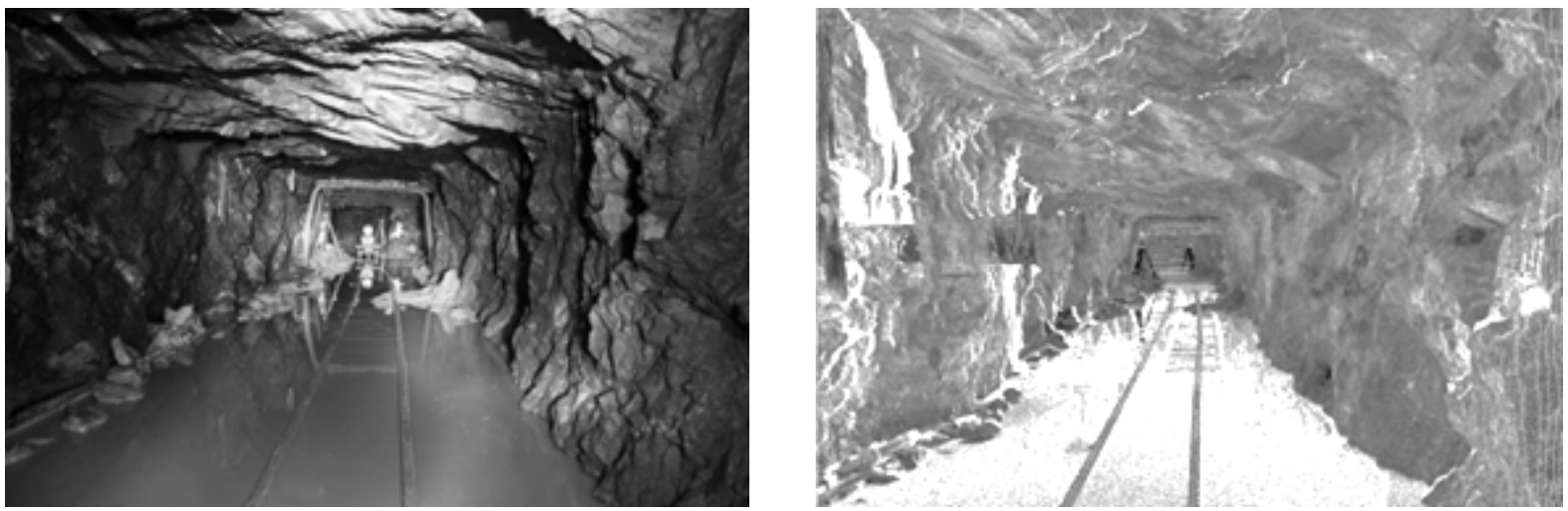

Fig. 6 Zlaté Hory-East site, 3rd floor, part of crosscut in Zlaté Hory-South site direction.

\section{DARKNESS AND USE OF THE INTEGRATED CAMERA}

Although the most commonly available commercial 3D laser scanners dispose of an integrated camera, the possibility of its use is directly proportional to the parameters of the resolution and sensitivity of the sensor. The camera is primarily designed to make the photographic documentation of the scanned area from the scanning position. The captured panorama image can be later used to change the color of point cloud to the real colors.

The general requirement for using the integrated camera in the underground environment is sufficient illumination of the surrounding area. Due to the lack of flash or any other type of illumination, it is not possible to use the integrated camera underground. As a suitable alternative to compensate this deficiency was using a trio of rechargeable LED lights with wattage of $20 \mathrm{~W}$ (the power is equal to conventional $100 \mathrm{~W}$ reflectors).

Since we don't need to move in total darkness, the use of these lights mounted on legs of scanner tripod $\left(120^{\circ}\right.$ shine angle) significantly increases the comfort of work. However, their use is still provided by the difficulties arising from the distance and intensity of the light source. There is a direct correlation valid, the larger the space, the greater power light source is needed, respectively the better sensitivity of the integrated camera sensor. Despite of the creation of very good light conditions in the tested area of mining corridors, the quality of resulting images did not meet our expectations. This was mainly due to insufficient quality of $4 \mathrm{Mpix}$ sensor placed in the integrated camera.

\section{PRACTICAL APPLICATION \\ THE COMBINATION OF LASER SCANNING AND PHOTO DOCUMENTATION}

Despite of all efforts, the possibility of using the integrated camera underground did not work. Another alternative was taking independent pictures of the entire area by high-quality camera. Figure 6 illustrates the combination of photography of the selected place acquired by DSLR camera and the corresponding selection of acquired point cloud. The intensity of the gray scale reflects the degree of reflectivity of each scanned point, resp. material. Combining the photo and scanning results, the fair idea of existing conditions of captured underground mining area can be obtained.

\section{SCANNING OF LINEAR MINE WORKINGS}

The possibility of using the laser scanning to capture the course of linear mining workings, i.e. mine corridors were tested on Zlaté Hory-East site, 3rd floor, in direction to the crosscut of Zlaté HorySouth site.

The mine trolley, on which the measuring equipment was stabilized, was used for scanning. This trolley was continuously moved along the rails (see Fig. 7) to a total of 10 scanning positions situated at a mutual distance of about $30 \mathrm{~m}$. Resulting scanned length of the corridor was approximately $250 \mathrm{~m}$. Finally, the Medium Resolution was used and final point cloud was formed by 145 million points.

\section{SCANNING STEP OPTIMIZATION}

With the selected step of about 30 meters, the scanned section was uneven and insufficient. In the next stage, it was therefore necessary to analyze the optimal scanning step in order to sufficiently capture the resulting point cloud of the entire corridor.

Therefore, about $75 \mathrm{~m}$ long corridor representing a classic example of mining gallery in this district was chosen for this purpose. Within the selected section we encountered grew rock and reinforced with steel, concrete and wooden casings, driven grids, rails, dry and wet floor and other materials. Light profile of the gallery was of approx. $3.7 \times 2.7 \mathrm{~m}$ in dimensions. There were 16 scanning positions located in this section at a distance of $5 \mathrm{~m}$ in total. From each separate position individual scan was performed. This was followed by analysis of the selection of optimal scanning step (see Fig. 7).

Obtained results of performed analysis completely confirmed that the scan step selection in the case of linear mine workings play important role. Scanning with steps of 5 and $10 \mathrm{~m}$ can be evaluated as optimal in these specific conditions, but it also demands the significant time on the implementation. Steps of 15 to $25 \mathrm{~m}$ can be evaluated as satisfactory. In this case, step above $25 \mathrm{~m}$ can be considered, as 


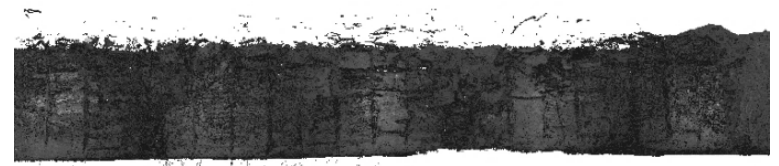

5 meters scanning step

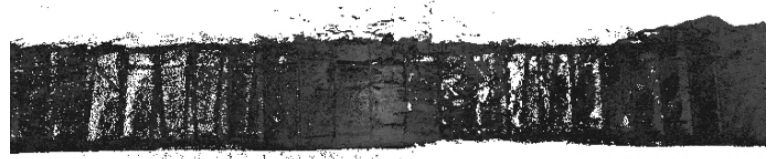

15 meters scanning step

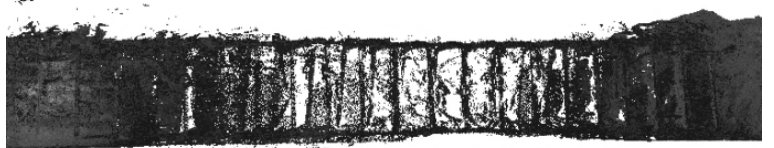

25 meters scanning step

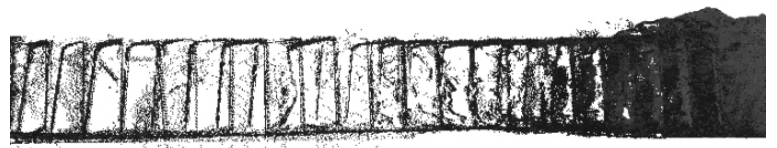

35 meters scanning step

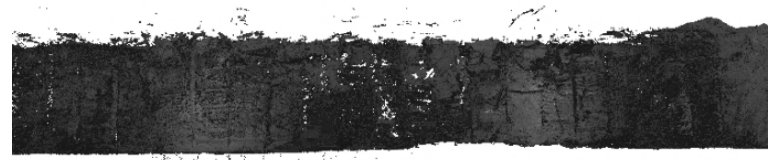

10 meters scanning step

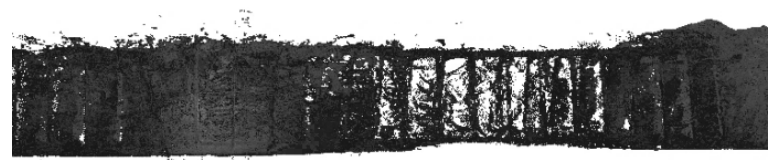

20 meters scanning step

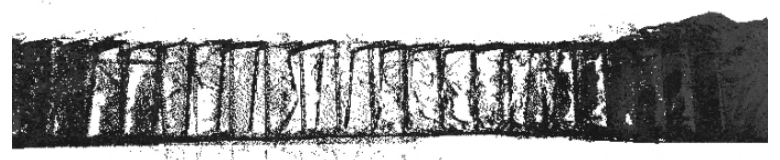

30 meters scanning step

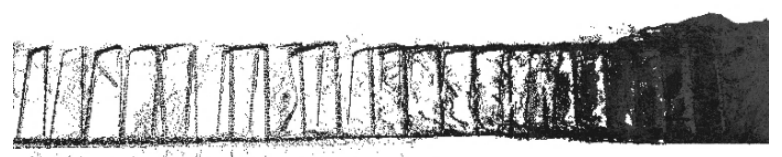

40 meters scanning step

Fig. 7 Effect of scanning positions distance on the description quality of the mine corridor.

unsatisfactory with a high degree of detail loss, and therefore, its use is not recommended in similar conditions. There is usually direct dependence between increasing profile of mine corridor and the longer step of scanning positions and vice versa.

The new knowledge of the optimal scanning steps was applied during subsequent scanning of helix gallery, representing the mine working minted downhill. The uniqueness of this space was the original installation of ventilation air pipes and other obstacles. The occurrence of such significant objects produces scanning shadows, which means, that areas are not sufficiently scanned. All those objects make the scanning very complicated. This is a very common phenomenon, which can be eliminated only by scanning from larger amount of scanning positions.

\section{SCANNING OF LARGE-SCALE MINE WORKINGS}

In the other campaigns, verification of scanning possibilities of large underground spaces was carried out. The large-scale mine workings include the works that are not of linear character and dimensions in proportion height $\mathrm{x}$ width $\mathrm{x}$ depth (length) are relatively similar. In mining and geotechnical practice, the chambers that were used in both ore mining and the extraction of brown coal within the various mining methods are classified as large-scale works.

For this purpose, the selected chamber situated on the second sublevel of the Zlaté Hory-East site was scanned. It is an area of irregular shape, with a maximum ceiling height of 30 meters and the width about $42 \mathrm{~m}$. Within Zlaté Hory deposit, it is a smaller chamber.
The entire chamber was scanned from 6 different positions in Medium Resolution (Fig. 4). The essential problem was the appropriate stabilization of targets in such enormous space. These targets are used for consecutive registration of point clouds into the compact one. The inability to use conventional scan targets is due to very poor visibility between laser and target and also due to very difficult movement on heap of material when the tilt in many parts approaches 40 degrees. This led to the proposal of so called tripletarget (see Fig. 8). It is designed based on appropriate combination of different parts of the available measuring equipment. Its advantage is in ability to rotate individual targets to the corresponding direction, where the target can be visible from any position in space. Its disadvantage is the short distance between single targets. This can cause the significant errors in the registration of point clouds. It means, that with increasing distance the error determining the spatial position of the scanned points increases. For this reason, using this alternative option is recommended only in occasional cases.

The resulting point cloud is represented by 90 million points. The entire scanned chamber is introduced by a pair of side views in Figure 9.

\section{CONVERGENCE PROFILES}

One of the goals of verification work was also to verify the possibility of using $3 \mathrm{D}$ scanner as a tool for measuring the convergence profiles (see Fig. 10).

The measurement results from the laser scanning technology convergence are comparable with the measurement results obtained by classical methods 

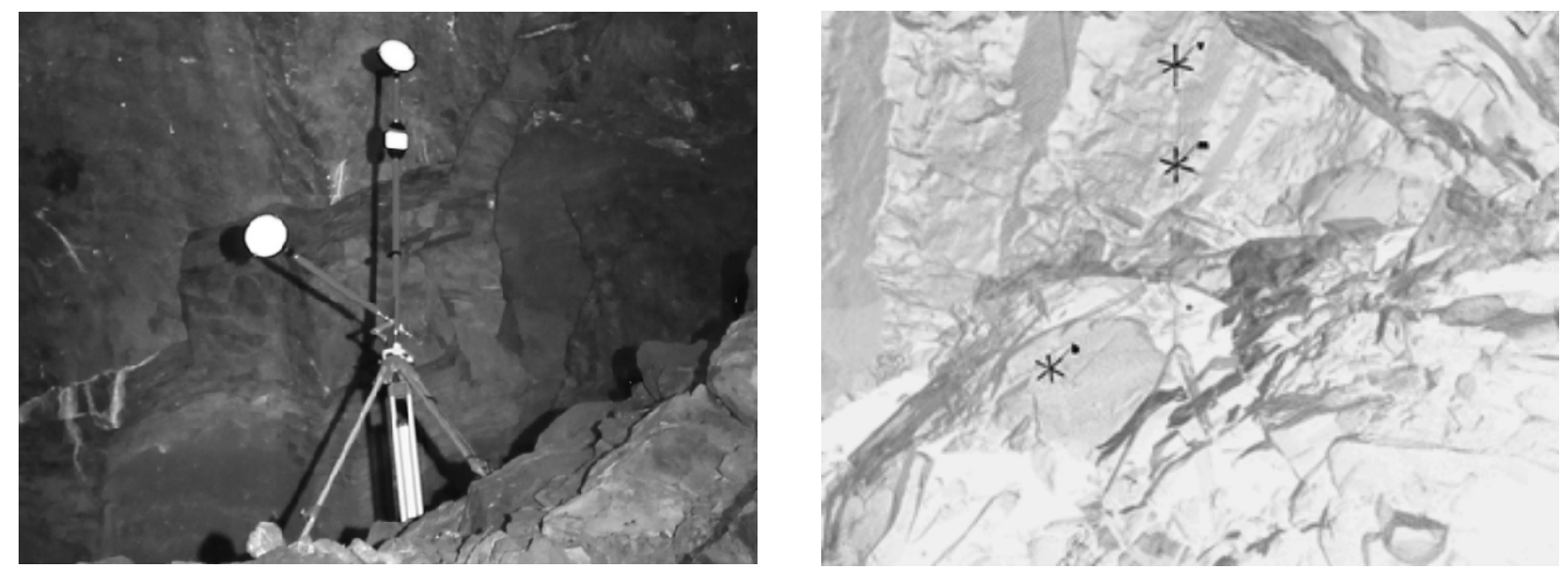

Fig. 8 Construction of triple-target and definition its targets centers in the point cloud.
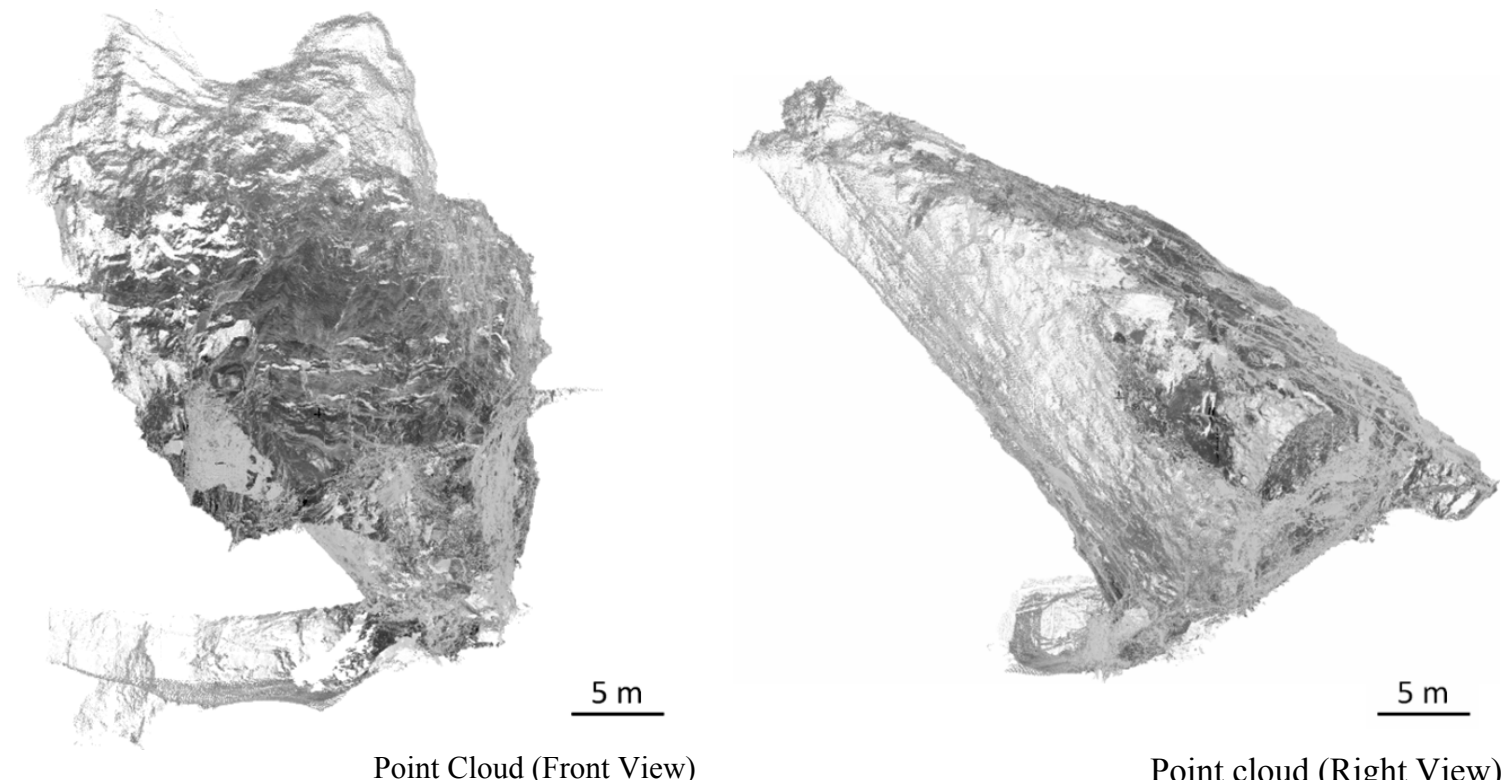

Point cloud (Right View)

Fig. 9 Scanning locality of Zlaté Hory-East site, chamber.

(manual reading of the band, resp. measurement by laser distance meter) reaching the measurement errors only in millimeters, depending on the position of the scanner to the scanned point. The advantage of using this technology is in ability to define the dimensions of mine workings not only in the specified profile, but also in any other location.

\section{OTHER POSSIBILITIES OF APPLICATION}

The technique and methods of scanning were followed by number of other tasks. The most noteworthy are:

- the assessment of stability conditions of mine workings on the example of repeated ceiling overhang monitoring of huge depression named Žebračka in the Zlaté Hory locality (Kuda et al., 2014),

- utilization of terrestrial 3D laser scanner for monitoring of changes and deformation of selected tailgate at Karviná Mine, locality Lazy (Kajzar and Kukutsch, 2014).

Apart from the applications mentioned above, this technology can find wide utilization in mining and geotechnical and geological practice, e.g. implementation of large volumetric calculation of various character, surveying of vertical mine workings, evaluation of slope movements and deformations on undermined territory, use in project activities, scanning of rock samples in the laboratory and many others.

\section{RESUME}

Knowledge of local conditions including the strict compliance of safety regulations and ability to predict the safety risks are important prerequisites for scanning in mine workings. It is important to realize, that scanning in a mine working means demands different amount of time and safety than in ordinary use (e.g. while scanning the facade of a resident building). The philosophy of the work is identical in both cases. However, there are many other external uncontrollable factors that significantly affect the possibility of using 3D laser scanning technology and lead to compromises and modifications of the standard methods and procedures. It is mainly the longer time-consumption and the environmental conditions mentioned above, for instance the dust, 


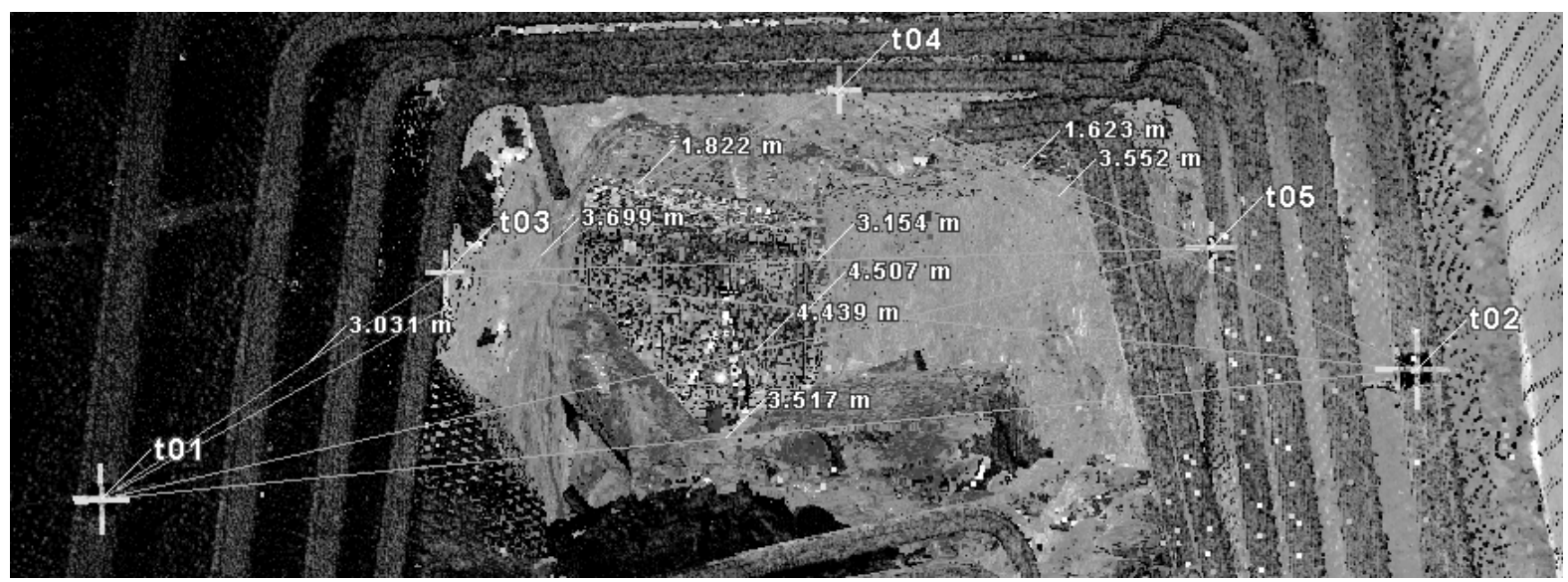

Fig. 10 Demonstration of convergence profiles.

humidity, spatial limitations such as the shape of mine workings and location of mining technology. It results in relatively accurate measurements with minimal risk despite of staying in such complicated conditions.

It should be also pointed out, that the authors are fully aware that the used device is not primarily designed for direct using in mines and in similarly hard terrain and climatic conditions. Its use in those extreme conditions was accompanied by series of preventive precautions (preventing the penetration of the dust into the device, condensation on the device, etc.) to eliminate the possibility of breaking the device accompanied by high degree of vigilance of handling the device itself.

Based on this experience and despite of described limitations we strongly believe, that with the current development boost of technology, the 3D scanning will become common technique used in mining, geotechnical and geological practice.

\section{ACKNOWLEDGEMENT}

This article was written in connection with a project of the Institute of Clean Technologies for Mining and Utilization of Raw Materials for Energy Use - Sustainability Program, reg. no. MSMT LO1406, which is supported by the Research and Development for Innovations Operational Programme financed by the Structural Funds of the Europe Union and the state budget of the Czech Republic.

\section{REFERENCES}

Buchroithner, M. F. and Gaisecker, T.: 2009, Terrestrial laser scanning for the visualization of a complex dome in an extreme Alpine cave system. PhotogrammetrieFernerkundung-Geoinformation, 4, 329-339.

Cosso, T., Ferrando, I. and Orlando, A.: 2014, Surveying and mapping a cave using 3D laser scanner: The open challenge with free and open source software. ISPRS International Archives of the Photogrammetry, Remote Sensing and Spatial Information Sciences, XL-5, 181-186.

Fekete, S., Diederichs, M. and Lato, M.: 2010, Geotechnical and operational applications for 3-dimensional laser scanning in drill and blast tunnels. Tunnelling and Underground Space Technology, 25, 614-628.
Feng, Q.: 2012, Practial application of 3D laser scanning techniques to undeground projects. ISRM-Swedish national task A survey of $3 \mathrm{~d}$ laser scanning techniques for application to rock mechanic. BeFo Report, 114, Stockholm, $67 \mathrm{pp}$.

Huber, D.F. and Vandapel, N.: 2003, Automatic 3D underground mine mapping. The 4th International Conference on Field and Service Robotics.

Jonsson, M., Bäckström, A., Feng, Q., Berglund, J., Johansson, M., Ivars, D.M. and Olsson, M.: 2009, Studies of factors that affect and controls the excavation damaged/disturbed zone (R-09-17). ÄSPÖ Hard Rock Laboratory. Svensk Kärnbränslehantering $\mathrm{AB}, 312 \mathrm{pp}$.

Kajzar, V. and Kukutsch, R.: 2014, Utilization of terrestrial 3D laser scanner for monitoring of changes and deformation of tailgate No $40703-1 \mathrm{~A}$ at Karvina Mine, locality Lazy. Proceedings of 5th International Colloquium on Geomechanics and Geophysics. Institute of Geonics AS CR, Ostrava.

Kuda, F., Kajzar, V., Divíšek, J. and Kukutsch, R.: 2014, Application of the terrestrial laser scanning in geoscience research (in Czech). Institute of Geonics AS CR, Ostrava, 53 pp.

Somervuori, P. and Lamberg, M.: 2009, Modern 3D photogrammetry method for rock mechanics, geological mapping, 3D model and documentation of open pit faces and tunnels. WSP Group, $16 \mathrm{pp}$.

Středa, V.: 2011, 3D basic motorway map - The Klimkovice tunnel. Tunel, 20, No. 4, 86-91, (in Czech).

Štroner, M., Pospíšil, J., Koska, B., Křemen, T., Urban, R., Smítka, V. and Třasák, P.: 2013, 3D scanning systems. Czech Technical University, Prague. 396 pp., (in Czech).

Vaníček, M., Chamra, S., Jirásko, D., Macháček, J., Vaníček, I., Záleský, J., Hada, A., Chaiyasarn, K. and Soga, K.: 2012, Methods of monitoring of metro lining in Prague. Geotechnical Aspects of Underground Construction in Soft Ground. Proceedings. 2012 CRC press, 1082 pp.

Vranka, V. and Kukutsch, R.: 2011, Problems of redevelopment of Zlaté Hory ore district. Proceedings of Mining Př́bram in science and technics conference, (in Czech).

Xiling, L., Xibing, L., Comber, A. and Kewei, L.: 2011, Underground cavity 3D detection using laser system (cross publication). Environmental Research Journal, 5, No. 5, 685-700. 